
\title{
$\begin{array}{ll}\text { Research Square } & \begin{array}{l}\text { Preprints are preliminary reports that have not undergone peer review. } \\ \text { They should not be considered conclusive, used to inform clinical practice, } \\ \text { or referenced by the media as validated information. }\end{array}\end{array}$
}

\section{Efficacy and Safety Testing of a COVID-19 Era Emergency Ventilator in a Healthy Rabbit Lung Model}

\author{
Luke A. White \\ LSU Health Shreveport \\ Benjamin S. Maxey \\ LSU Health Shreveport \\ Giovanni F. Solitro \\ LSU Health Shreveport \\ Hidehiro Takei \\ LSU Health Shreveport \\ Steven A. Conrad \\ LSU Health Shreveport \\ J. Steven Alexander ( $\boldsymbol{\sim}$ jonathan.alexander@lsuhs.edu ) \\ LSU Health Shreveport
}

\section{Research Article}

Keywords: ventilator, emergency, low-cost, COVID-19, rabbit, lung

Posted Date: December 15th, 2021

DOI: https://doi.org/10.21203/rs.3.rs-1139198/v1

License: (0) (1) This work is licensed under a Creative Commons Attribution 4.0 International License. Read Full License

Version of Record: A version of this preprint was published at BMC Biomedical Engineering on March 14th, 2022. See the published version at https://doi.org/10.1186/s42490-022-00059-x. 


\section{Abstract}

Background: The COVID-19 pandemic revealed a substantial and unmet need for low-cost, easily accessible mechanical ventilation strategies for use in medical resource-challenged areas. Internationally, several groups developed non-conventional COVID-19 era emergency ventilator strategies as a stopgap measure when conventional ventilators were unavailable. Here, we compared our FALCON emergency ventilator in a rabbit model and compared its safety and functionality to conventional mechanical ventilation.

Methods: New Zealand white rabbits $(n=5)$ received mechanical ventilation from either the FALCON or a conventional mechanical ventilator (Engström Carestation ${ }^{\mathrm{TM}}$ ) for 1 hour each. Airflow and pressure, blood $\mathrm{O}_{2}$ saturation, end tidal $\mathrm{CO}_{2}$, and arterial blood gas measurements were measured. Additionally, gross and histological lung samples were compared to spontaneously breathing rabbits $(n=3)$ to assess signs of ventilator induced lung injury.

Results: All rabbits were successfully ventilated with the FALCON. At identical ventilator settings, tidal volumes, pressures, and respiratory rates were similar between both ventilators, but the inspiratory to expiratory ratio was lower using the FALCON. End tidal $\mathrm{CO}_{2}$ was significantly higher on the FALCON, and arterial blood gas measurements demonstrated lower arterial partial pressure of $\mathrm{O}_{2}$ at 30 minutes and higher arterial partial pressure of $\mathrm{CO}_{2}$ at 30 and 60 minutes using the FALCON. However, when ventilated at higher respiratory rates, we observed a stepwise decrease in end tidal $\mathrm{CO}_{2}$. Poincaré plot analysis demonstrated small but significant increases in short-term and long-term variation of peak inspiratory pressure generation from the FALCON. Wet to dry lung weight and lung injury scoring between the mechanically ventilated and spontaneously breathing rabbits were similar.

Conclusions: Although conventional ventilators are always preferable outside of emergency use, the FALCON ventilator safely and effectively ventilated healthy rabbits without lung injury. Emergency ventilation using accessible and inexpensive strategies like the FALCON may be useful for communities with low access to medical resources and as a backup form of emergency ventilation.

\section{Background}

On March 11, 2020, worldwide infection with the novel SARS-CoV-2 virus/COVID-19 was declared a pandemic by the World Health Organization [1, 2]. Initial reports described severe respiratory disease, including acute respiratory distress syndrome (ARDS) that, in many cases required ICU level care [3, 4]. Mechanical ventilation remains a pillar of supportive care for COVID-19 induced ARDS [5, 6]. Concerns that demand for accessible and functional mechanical ventilators could easily exceed supply and would lead to extraordinarily difficult triage decisions by healthcare providers to prioritize resource allocation for patients $[7,8]$. These issues persist and are too often encountered in low-and middle-income nations, where medical-grade equipment and supplies become inaccessible $[9,10]$.

For these reasons, many international scientific and clinical engineering groups began efforts to develop non-traditional, emergencyuse mechanical ventilation approaches for use in medical resource-challenged settings $[11,12]$. It was thought that such "COVID-19 era emergency ventilators" (CEEVs) could potentially be used on patients with mild to moderate cases of ARDS to allow for reallocation of more sophisticated ICU ventilators to patients with more severe ARDS, preventing the need to withdraw or refuse mechanical ventilation to a patient due to lack of supply [13]. Similar allocation strategies have been successfully employed using anesthetic gas machines in especially hard-hit regions, such as New York City and Northern Italy [14, 15]. Likewise, CEEVs could provide temporary but critical solutions when supplies of more sophisticated ventilators run short and must be restored through redistribution, an ordinarily lengthy process that was greatly exacerbated by pandemic-associated supply chain interruptions and import restrictions $[16,17]$.

Many designs for CEEVs have been advanced and publicized globally with assembly information and end-user instructions uploaded on websites [18-21]. Less commonly, these designs have undergone more rigorous testing, including safety and efficacy testing in preclinical animal models [22-27]. The lack of testing is likely due to resource and time constraints for performing such tests amidst a pandemic, and the urgency to disseminate the design in a timely manner.

We previously described and tested our own CEEV design called the FALCON [28]. The FALCON can be assembled from low-cost, offthe-shelf components. A unique characteristic of the FALCON is its ability to function immediately and predictably following assembly, without the need to initialize microcontroller programming. Despite its deliberately simple design, benchtop testing of the 
FALCON demonstrated its robustness in performing accurately and consistently. However, the efficacy and safety of the FALCON was not tested in vivo in the context of the complex physiology of an animal model.

In our present study, we tested the utility and safety of the FALCON in a healthy rabbit lung model and compared its function to an ICU rated mechanical ventilator. The crossover design of the study helped clarify subtle performance differences between these ventilators. As such, this study design could also be more broadly applied to other CEEVs and future novel ventilators to test their utility beyond benchtop testing in a more meaningful, clinical-like scenario.

\section{Materials And Methods}

The study was conducted with the approval of the Animal Care and Use Committee of LSU Health Shreveport (study protocol \#S-21001), and all animals and procedures were carried out in compliance with the Institution's policies involving the care and use of laboratory animals. All methods are reported in accordance with ARRIVE guidelines. All experiments and sample collections were performed by the same technician.

\subsection{FALCON Ventilator and Ventilation Circuit Assembly}

The FALCON ventilator (Figure 1a) was assembled as previously described [28], with a few notable modifications. The wiring between the air pump, timer relay, and pulse width modulators were modified (Figure 1b) so that the current delivered to the fan was reversed during the expiratory phase. While the inspiratory pulse width modulator still controlled the peak inspiratory pressure (PIP), the expiratory pulse width modulator was used to actively slow down the turbine, rather than relying on the turbine to spin down passively, allowing for greater respiratory rates. With this wiring scheme change, the expiratory pulse width modulator lost the capability to control positive end expiratory pressure (PEEP), which was now set with a PEEP valve. This wiring scheme led to an increase in temperature experienced by the solenoid in the timer relay, potentially causing the solenoid to stall. To prevent overheating, a cooling fan (12V DC brushless muffin fan, Hong Xing Shu Electronics Company LTD, Shenzhen, Guangdong, China) was fitted into housing above the solenoid.

The ventilator circuit for the FALCON was assembled from conventional continuous positive airway pressure (CPAP) respiratory tubing and spare parts from a bag valve mask (BVM). The three-way, two-position pneumatically driven valve found on the outlet side of an infant BVM (SPUR II® infant model, AMBU® A/S, Columbia, MD, USA) was utilized to connect the FALCON to the rabbit and minimize the dead space. The FALCON was connected to the inspiratory side of the valve with silicone rubber fitted CPAP hosing (6 ft. x 19 mm inner diameter, Philips Respironics, Murrysville, PA), while a PEEP valve (Disposable PEEP Valve 20, AMBUß A/S, Columbia, MD, USA) was connected on the expiratory side. The common line was used to connect the ventilator circuit to the rabbit (Figure 2a). During inspiration, the FALCON's air pump generated a positive differential pressure gradient, causing the valve to open between the inspiratory side and the common (Figure $2 \mathrm{~b}$ ). During expiration, the turbine in the air pump rapidly slowed down, and the pressure on the inspiratory limb was lower than the common. The valve then shut toward the inspiratory limb and opened to the expiratory outlet (Figure 2c). Air flowed out the expiratory outlet and through the PEEP valve until the pressure in the common fell to the set PEEP (Figure 2d).

\subsection{Animals and experimental design}

The experiments were performed with healthy male New Zealand white rabbits (mechanical ventilation, or MV, group; $n=5$ ), weighing between 2.0 to $4.0 \mathrm{~kg}$. No exclusion criteria were set for the experiments, and all animals were included in the study.

In this crossover study, the rabbits received ventilation from both a hospital grade ventilator (Engström Carestation ${ }^{\text {TM }}$, General Electric Healthcare, Chicago, IL) and the FALCON for 1 hour each (Figure 3). After determination of baseline ventilation settings on the Carestation, the rabbits were randomized (block randomization of 2 groups with 1 block size of 4 [29], final rabbit assigned a group via simple randomization from a coin flip) to receive ventilation either from the Carestation first followed by the FALCON ( $n=$ 3 ), or from the FALCON first followed by the Carestation $(n=2)$. Afterwards, the rabbits were euthanized, and samples of lung tissue were collected. One rabbit from the MV group underwent additional ventilation on the FALCON for approximately 20 minutes.

Additionally, samples of lung tissue from spontaneously breathing healthy male New Zealand white rabbits $(\mathrm{SB} ; \mathrm{n}=3)$ were taken to serve as a healthy control.

\subsection{Experimental Protocol}


Anesthesia was induced with an intramuscular injection of xylazine $(4 \mathrm{mg} / \mathrm{kg})$ followed by a ketamine + acepromazine $(40 \mathrm{mg} / \mathrm{kg}$ and $0.75 \mathrm{mg} / \mathrm{kg}$, respectively) cocktail intramuscular injection, and the rabbit was placed in the supine position on a heating pad (see Figure 4 for experimental setup). A rectal thermometer was inserted for core body temperature monitoring, and a pulse oximetry sensor was placed along a hind paw for continuous monitoring of oxygen saturation and pulse rate. A nosecone was placed and supplemental oxygen and isoflurane anesthetic (up to $5 \%$, as needed) were administered. A midline incision along the ventral neck was made, and the external jugular vein was isolated and cannulated with a double-lumen venous catheter for continuous infusion of a ketamine + xylazine cocktail (10 mg/kg/hr and $4 \mathrm{mg} / \mathrm{kg} / \mathrm{hr}$, respectively), and the isoflurane administration was stopped. Additionally, an intravenous infusion of fluids ( $5 \%$ dextrose with $0.9 \%$ saline) was begun and adjusted, when needed, for a total volume replacement of $4 \mathrm{~mL} / \mathrm{kg} / \mathrm{hr}$. The common carotid was isolated and cannulated with a single lumen arterial catheter, and a pressure transducer was connected for continuous arterial blood pressure monitoring. Arterial blood was intermittently sampled at the arterial cannula for arterial blood gas (ABG) measurements. A horizontal incision was made in the trachea, and an endotracheal tube (3.0 inner diameter) was introduced and secured. The endotracheal tube was connected to the Carestation ventilator circuit, set in pressure control ventilation with the initial settings of $\mathrm{PIP}=11 \mathrm{~cm} \mathrm{H}_{2} \mathrm{O}, \mathrm{PEEP}=3 \mathrm{~cm} \mathrm{H} \mathrm{H}_{2} \mathrm{O}$, respiratory rate (RR) $=40 \mathrm{breaths} / \mathrm{min}$, and inspiratory time to expiratory time (I:E) ratio $=1: 1$. A bolus of cisatracurium besylate $(0.12 \mathrm{mg} / \mathrm{kg})$ was intravenously administered to depress spontaneous breathing, and a continuous intravenous infusion (1.0 to $2.0 \mu \mathrm{g} / \mathrm{kg} / \mathrm{min}$ ) was then started to maintain cessation of spontaneous respiration. During baseline ventilation determination, the target PIP (PIP target $)$ and PEEP $\left(P E E P_{\text {target }}\right)$ were determined by adjusting the PIP and PEEP to achieve a tidal volume $\left(V_{T}\right)<10 \mathrm{~mL} / \mathrm{kg}$, blood oxygen saturation $\left(\mathrm{SpO}_{2}\right)>95 \%$, and end tidal carbon dioxide $\left(\mathrm{EtCO}_{2}\right)$ between 35 and $45 \mathrm{~cm} \mathrm{H}_{2} \mathrm{O}$ for at least 10 minutes. These ventilation settings remained constant throughout the remainder of each experiment, as this provided a means to directly compare the ventilator performance between the Carestation and FALCON, given identical ventilation settings. The rabbit was mechanically ventilated for 1 hour each on the Carestation and FALCON, and the order of ventilation was randomly assigned to each rabbit prior to the experiment. After ventilation with both ventilators, the rabbit was euthanized with intravenous administration of pentobarbital $(100 \mathrm{mg} / \mathrm{kg})$.

In this experimental protocol, baseline ventilation with the Carestation was used to set the ventilation settings for both the Carestation and FALCON for the rest of the experiment, meaning that the settings may not be optimal for the FALCON. Although the FALCON may perform differently than the Carestation at identical ventilation settings, an alteration to those settings (e.g., RR), given certain constraints to PIP and PEEP may allow for more appropriate ventilation with the FALCON. To test this, one rabbit from the MV group was ventilated with the FALCON at varying RRs $(30,40,60$, and 120 breaths/min) for 5 minutes each with constant pressure settings $\left(\mathrm{PIP}_{\text {target }}=11 \mathrm{cmH}_{2} \mathrm{O}, \mathrm{PEEP}_{\text {target }}=3 \mathrm{cmH}_{2} \mathrm{O}\right)$. This was performed as an additional step after ventilating with the Carestation and FALCON for 1 hour each.

In the SB rabbit group $(\mathrm{n}=3)$, anesthesia was induced with a xylazine $(4 \mathrm{mg} / \mathrm{kg})$ intramuscular injection followed by a ketamine + acepromazine (40 mg/kg and $0.75 \mathrm{mg} / \mathrm{kg}$, respectively) cocktail intramuscular injection. A nosecone was placed, and supplemental oxygen and isoflurane (5\%) were administered. A marginal ear vein catheter was inserted, and intravenous pentobarbital (100 $\mathrm{mg} / \mathrm{kg}$ ) was administered for euthanasia.

\subsection{Physiological and respiratory mechanics measurements}

Invasive arterial pressure was continuously measured at the arterial cannulation site with pressure transducers (Cobe Laboratories, McHenry, Illinois, United States) connected to a blood pressure monitor (Pressure Monitor BP-1, World Precision Instruments, Sarasota, Florida, United States). The blood pressure monitor was connected to a data acquisition unit (PowerLab 4/30, AD Instruments, Colorado Springs, Colorado, United States) to transfer readings to a computer (Optiplex 7070, Dell Inc., Round Rock, TX) for recording with the manufacturer's software (Labchart 7, AD Instruments, Colorado Springs, Colorado, United States). Mean arterial pressure (MAP) was determined using the recorded traces with the manufacturer's software. $\mathrm{SpO}_{2}$ and pulse rate were continuously measured with a veterinary pulse oximeter (Contec CMS60D-VET pulse oximeter, Contec Medical Systems, Qinhuangdao, China) and recorded to the computer with the manufacturer's software. $\mathrm{EtCO}_{2}$ and core body temperature were continuously measured with a physiological monitoring system (CapnoScan, Kent Scientific, Torrington, Connecticut, United States), and data were exported digitally to the computer following the manufacturer's instructions.

Airflow measurements were taken at the common line in the ventilator circuits utilizing a proximal airflow sensor (SFM3400-D, Sensirion AG, Staefa, Switzerland), which had a dead space volume less than $1 \mathrm{~mL}$. Data from the sensor were transferred to the computer with a USB sensor cable (Evaluation Kit EK-F3x-CAP, Sensirion AG, Staefa, Switzerland) and accompanying software 
provided by the manufacturer. To record pressure waveforms, two barometric pressure sensors (DPS310, Infineon Technologies AG, Neubiberg, Germany) placed and sealed in custom stereolithography 3D printed housing (surgical guide resin printed with the Formlabs Form 2 printer, Somerville, Massachusetts, United States). Unlike the flow sensor, the pressure sensors had considerable dead-space (greater than $10 \mathrm{~mL}$ ), so two pressure sensors were used with the FALCON ventilator circuit: one on the inspiratory line just before the 3-way, 2-position valve to record pressures during inspiration, and one on the expiratory side, just before the PEEP valve to record pressures during expiration. Only one pressure sensor was used with the Carestation ventilator circuit, just prior to the wye-piece on the inspiratory line, as the inspiratory and expiratory lines were not isolated from each other by a valve. Data from pressure sensors were sent to the computer via USB, following the instructions provided by the manufacturer. Using custom code written in Python (version 3.7.2, Python Software Foundation, Beaverton, Oregon, United States), pressure readings captured by the two pressure sensors from the FALCON were combined to generate a single pressure waveform. Additionally, custom code was written in Python to determine $\mathrm{V}_{\mathrm{T}}, \mathrm{RR}$, I:E ratio, PIP, and PEEP for each respiratory cycle from the recorded flow and pressure waveforms. $V_{T} s$ were calculated from the areas under the flow waveform during inspiration. RRs and I:E ratios were determined from analysis of the flow waveform. PIPs and PEEPs were determined from the recorded pressure waveforms, and difference in PIP and

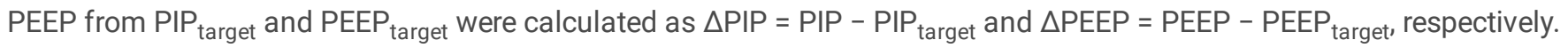

\subsection{Blood gas analysis}

A blood gas analyzer (Radiometer ABL800 Flex, Radiometer Medical, Bronshoj, Denmark) was used to determine arterial partial pressure of oxygen $\left(\mathrm{PaO}_{2}\right)$, arterial partial pressure of carbon dioxide $\left(\mathrm{PaCO}_{2}\right), \mathrm{pH}$, and lactate concentrations from arterial blood samples taken after 30 and 60 minutes of ventilation with both the Carestation and FALCON.

\subsection{Tissue Fixation and Processing}

Lung tissue was fixed in $4 \%$ formaldehyde for 24 hours using the tracheal ligation technique [30]. Briefly, the endotracheal tube was removed, and the trachea was ligated with 4-0 suture below the tracheal incision site to keep the lungs inflated. A thoracotomy was carefully performed, the lungs were inspected for pneumothorax. The heart and lungs were removed en bloc, ensuring the lungs remained inflated. The right main bronchus was also ligated with 4-0 suture to prevent lung deflation, and a sample of the right anterior lobe was excised for wet to dry weight measurements. A weight was then tied to the trachea, lungs, and heart and the unit was submerged in $4 \%$ formaldehyde for 24 hours.

\subsection{Lung Wet Weight to Dry Weight Measurements}

Samples of lung tissue from the right anterior lobe were excised, and weight measurements were taken before and after drying at $47^{\circ} \mathrm{C}$ for 96 hours. The wet to dry weight ratio was calculated as the wet weight divided by the dry weight.

\subsection{Lung Histology}

After fixation, a section of the middle portion of the left posterior lobe was excised and processed prior to embedding in paraffin, following the institution's standard protocol. Tissue sections $(10 \mu \mathrm{m})$ were stained with hematoxylin and eosin (H\&E). A pathologist blinded to group allocations performed ventilator induced lung injury (VILI) scoring, as previously described [31], on three consecutive sections. Four metrics (alveolar congestion, hemorrhage, leukocyte infiltration, and thickness of alveolar wall) were scored on a 0-4 scale, where 0 represented normal lung, 1 mild (less than 25\%) lung involvement, 2 moderate ( 25 to $50 \%$ ) lung involvement, 3 severe (50 to $75 \%$ ) lung involvement, and 4 very severe (75 to $100 \%$ ) lung involvement, and an overall score was calculated as the average of all four metrics.

\subsection{Poincaré Plot Analysis}

Poincaré plot analysis can be used to evaluate the variation of data in a time-series [32]. In the Poincaré plot, a datapoint at time $n$ is plotted in the abscissa against its subsequent datapoint at time $n+1$ along the ordinate. The standard deviation of this dataset perpendicular to the line of identity $n=n+1$ is defined as SD1 and is a measure of variation from one datapoint to the immediate subsequent datapoint (short-term variation), while the standard deviation parallel to the line of identity (SD2) is a measure of all other variation (long-term variation). Poincaré plots were constructed for the PIP and PEEP generated by the Carestation and FALCON for each rabbit for analysis of short- and long-term variation in pressure generation.

\subsection{Statistical Analysis}


Data are presented as mean \pm standard deviation, unless otherwise noted. For paired data, the Shapiro-Wilk test was performed to assess normality. For the data normally distributed, differences between the groups were evaluated with a two-tailed paired Students $t$-test. If the data were not normally distributed, the two-tailed Wilcoxon signed rank test was performed instead. Sample size for the crossover ventilation experiments $(n=5)$ was determined using an online sample size calculator (power $=0.8, a=0.05)$ assuming that a physiologically significant difference in $\mathrm{SpO}_{2}$ between the FALCON and Carestation would occur if the mean paired differences were $10 \%$ with a standard deviation of paired differences of $5 \%$ [33]. For unpaired data, the two-tailed Mann-Whitney $U$ test was performed. A $p$ value $<0.05$ was considered statistically significant. Besides the sample size determination, all statistics were performed with the Graphpad prism statistics software (version 9.2, Graphpad, San Diego, CA).

\section{Results}

\subsection{The FALCON generated $V_{T}$, PIP and PEEP comparably to the Carestation but spent less time in inspiration.}

Five $(n=5)$ rabbits in the experimental group were alternatively ventilated with the FALCON and Carestation for 1 hour each. All five rabbits survived to the end of the trial and demonstrated similar mean arterial blood pressures $(58 \pm 13 \mathrm{mmHg}$ Carestation, $58 \pm 9$ $\mathrm{mmHg}$ FALCON, $p=0.87)$ and pulse rates $(168 \pm 20$ beats $/ \mathrm{min}$ Carestation, $170 \pm 23$ beats $/ \mathrm{min}$ FALCON, $p=0.33)$ for the duration of the experiment (Figure 5).

Under similar conditions, compared to the Carestation, the flow waveform of the FALCON peaked at lower values and were more elongated (Figure $6 a$ ), demonstrating that under similar settings, $V_{T}$ was achieved less quickly with the FALCON compared to the Carestation. Additionally, pressure waveforms for the Carestation were more square-like, while the waveforms generated by the FALCON were more sawtooth (Figure 6b), indicating that PIP and PEEP were reached later in the inspiratory and expiratory phases.

One-minute samples of the flow and pressure waveforms, taken at the start of the 1-hour ventilation period and again every 10 minutes thereafter for both FALCON and Carestation, were analyzed to determine the average $\mathrm{V}_{\mathrm{T}}, \triangle \mathrm{PIP}, \triangle \mathrm{PEEP}, \mathrm{RR}$ and I:E ratios for each rabbit during the ventilation period (Figure $6 \mathrm{c}-\mathrm{g})$. Average $\mathrm{V}_{\mathrm{T}} \mathrm{s}(7.1 \pm 0.6 \mathrm{~mL} / \mathrm{kg}$ Carestation, $6.8 \pm 1.7 \mathrm{~mL} / \mathrm{kg} \mathrm{FALCON}, p=0.77)$, $\triangle$ PIPs $\left(0.3 \pm 0.2 \mathrm{~cm} \mathrm{H}_{2} \mathrm{O}\right.$ Carestation, $0.5 \pm 0.5 \mathrm{~cm} \mathrm{H}_{2} \mathrm{O}$ FALCON, $\left.p=0.16\right), \Delta$ PEEPs $\left(-0.2 \pm 0.1 \mathrm{~cm} \mathrm{H}_{2} \mathrm{O}\right.$ Carestation, $-0.3 \pm 0.2 \mathrm{~cm}$ $\mathrm{H}_{2} \mathrm{O}$ FALCON, $\left.p=0.95\right)$ and RRs ( $40.0 \pm 0.1$ breaths/min Carestation, $39.7 \pm 0.5$ breaths/min FALCON, $\left.p=0.19\right)$ were not significantly different between ventilation with the FALCON versus the Carestation. However, the I:E ratios generated by the FALCON were significantly lower compared to the Carestation ( $1.03 \pm 0.03$ Carestation, $0.67 \pm 0.05$ FALCON, $\left.{ }^{\star \star \star \star} p<0.0001\right)$, despite the timer relay on the FALCON being set at a 1:1 ratio. This appeared to indicate that using comparable settings, less time was spent in inspiration and more time in expiration with the FALCON for each respiratory cycle.

\subsection{At identical settings, oxygen and carbon dioxide gas exchange occurred less with the FALCON compared to the Carestation.}

At identical settings, less time was spent in inspiration with the FALCON versus the Carestation, and $V_{T}$ was achieved less quickly. This may have caused a lower rate of gas exchange to occur with the FALCON. ABGs taken at 30 and 60 minutes (Table 1) demonstrated a moderately lower but significant decrease in $\mathrm{PaO}_{2}$ at 30 minutes with the FALCON $(77.0 \pm 9.9 \mathrm{mmHg})$ versus the Carestation $\left(90.7 \pm 18.6 \mathrm{mmHg}\right.$, $\left.{ }^{\star} p<0.05\right)$. Despite this decrease, arterial saturation could be adequately maintained. $\mathrm{PaCO}_{2}$ levels were elevated at both the 30-minute $(33.4 \pm 3.4$ Carestation, $45.2 \pm 5.5 \mathrm{mmHg}$ FALCON, $* \star p<0.01)$ and 60 -minute $(32.1 \pm 4.1 \mathrm{mmHg}$ Carestation, $45.1 \pm 7.7 \mathrm{mmHg}$ FALCON, ${ }^{* *} p<0.01$ ) timepoints with the FALCON versus the Carestation, and this led to a less alkalotic $\mathrm{pH}$ at both timepoints (at 30 minutes, $7.572 \pm 0.069$ Carestation, $7.461 \pm 0.074 \mathrm{FALCON}$, ${ }^{\star \star} p<0.01$; at 60 minutes, $7.564 \pm 0.061$ Carestation, $7.450 \pm 0.112$ FALCON, $* \star p<0.01$ ). Additionally, blood lactate levels were not different between the FALCON and Carestation groups (at 30 minutes, $2.7 \pm 1.4 \mathrm{mmol} / \mathrm{L}$ Carestation, $2.4 \pm 1.3 \mathrm{mmol} / \mathrm{L}$ FALCON, $p=0.29$; at 60 minutes, $2.9 \pm 1.4$ $\mathrm{mmol} / \mathrm{L}$ Carestation, $2.7 \pm 1.5 \mathrm{mmol} / \mathrm{L}$ FALCON, $p=0.78)$. 
Table 1

Arterial Blood Gas Measurements.

\begin{tabular}{|c|c|c|c|c|c|c|}
\hline \multirow[t]{2}{*}{ ABG Measurement } & \multicolumn{3}{|l|}{30 minutes } & \multicolumn{3}{|l|}{60 minutes } \\
\hline & $\begin{array}{l}\text { Carestation } \\
(n=5)\end{array}$ & $\begin{array}{l}\text { FALCON } \\
(n=5)\end{array}$ & $p$ value $^{\dagger}$ & $\begin{array}{l}\text { Carestation } \\
(n=4)\end{array}$ & $\begin{array}{l}\text { FALCON } \\
(n=5)\end{array}$ & $p$ value $^{\ddagger}$ \\
\hline $\mathrm{PaO}_{2}(\mathrm{mmHg})$ & $90.7 \pm 18.6$ & $77.0 \pm 9.9$ & * & $96.8 \pm 17.7$ & $80.8 \pm 14.9$ & 0.38 \\
\hline $\mathrm{PaCO}_{2}(\mathrm{mmHg})$ & $33.4 \pm 3.4$ & $45.2 \pm 5.5$ & ** & $32.1 \pm 4.1$ & $45.1 \pm 7.7$ & ** \\
\hline $\mathrm{pH}$ & $7.572 \pm 0.069$ & $7.461 \pm 0.074$ & $\star \star$ & $7.564 \pm 0.061$ & $7.450 \pm 0.112$ & ** \\
\hline lactate $(\mathrm{mmol} / \mathrm{L})$ & $2.7 \pm 1.4$ & $2.4 \pm 1.3$ & 0.29 & $2.9 \pm 1.4$ & $2.7 \pm 1.5$ & 0.78 \\
\hline
\end{tabular}

Data are presented with mean \pm standard deviation. + Reported $p$ value from two-tailed paired Students $t$-test $(n=5$ rabbits, $a=0.05)$ of the ABG measurements from 30 minutes of ventilation with either the Carestation or FALCON. ‡ Reported $p$ value from either the paired Students $t$-test $\left(\mathrm{PaCO}_{2}, \mathrm{pH}\right.$ and lactate) or Wilcoxon signed-rank test $\left(\mathrm{PaO}_{2}\right)$ of $A B G$ measurements from 60 minutes of ventilation with either the Carestation ( $n=4$ rabbits due to unanticipated inaccessibility of the ABG machine for one rabbit's sample) or FALCON ( $\mathrm{n}=5$ rabbits, $\mathrm{a}=0.05$, unpaired data point was ignored in the calculation). ${ }^{\star} p<0.05,{ }^{\star \star} p<0.01, \mathrm{ABG}$ arterial blood gas, $\mathrm{PaCO}_{2}$ arterial partial pressure of carbon dioxide, $\mathrm{PaO}_{2}$ arterial partial pressure of oxygen.

The average $\mathrm{SpO}_{2}$ over the course of ventilation for the FALCON trended lower compared to the Carestation (Figure 7a; $96 \% \pm 2 \%$ Carestation, $93 \% \pm 4 \% \mathrm{FALCON}, p=0.05$ ). Furthermore, the average $\mathrm{EtCO}_{2}$ was greater for the FALCON than the Carestation (Figure $7 \mathrm{~b} ; 32 \pm 4 \mathrm{mmHg}$ Carestation, $45 \pm 5 \mathrm{mmHg}$ FALCON, $* \star p<0.01)$.

\subsection{By adjusting the respiratory rate, the FALCON achieved a broad range of adequate minute ventilation rates at given target PIP and} PEEP.

One rabbit was ventilated with the FALCON for 5 minutes at varying target RRs (30,40, 60, and 120 breaths/min) to assess the ability of the FALCON to provide different minute ventilations (minute V), given specific constraints on PIP and PEEP. The FALCON was

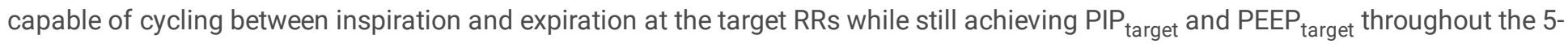
minute ventilation period (Table 2; maximal average $\triangle \mathrm{PIP}=1.7 \pm 0.3 \mathrm{cmH}_{2} \mathrm{O}$ at target $\mathrm{RR}=60 \mathrm{breaths} / \mathrm{min}$; maximal average $\triangle \mathrm{PEEP}$ $=0.9 \pm 0.1 \mathrm{cmH}_{2} \mathrm{O}$ at target $\mathrm{RR}=120$ breaths $/ \mathrm{min}$ ). The average $\mathrm{V}_{\mathrm{T}}$ over the 5 -minute ventilation period remained above $5 \mathrm{~mL} / \mathrm{kg}$ for $\mathrm{RR}=30,40$, and 60 breaths $/ \mathrm{min}$, although this fell to $2.9 \mathrm{~mL} / \mathrm{kg}$ at RR $=120$ breaths $/ \mathrm{min}$. The average $\mathrm{SpO}_{2}$, when sampled from the last minute of ventilation, remained above $97 \%$ at all respiratory rates.

Table 2

FALCON Respiratory Mechanics and $\mathrm{SpO}_{2}$ at Different Respiratory Rates

\begin{tabular}{|c|c|c|c|c|c|}
\hline Target RR (breaths/min) & Measured RR (breaths/min) & $\mathrm{V}_{\mathrm{T}}(\mathrm{mL} / \mathrm{kg})$ & $\Delta \mathrm{PIP}\left(\mathrm{cm} \mathrm{H}_{2} \mathrm{O}\right)$ & $\triangle$ PEEP $\left(\mathrm{cm} \mathrm{H}_{2} \mathrm{O}\right)$ & $\mathrm{SpO}_{2}(\%)$ \\
\hline 30 & $29.8 \pm 2.0$ & $5.8 \pm 0.4$ & $1.0 \pm 0.4$ & $-0.4 \pm 0.4$ & 98 \\
\hline 40 & $39.8 \pm 0.2$ & $5.7 \pm 0.5$ & $0.1 \pm 0.1$ & $-0.7 \pm 0.6$ & 99 \\
\hline 60 & $59.4 \pm 3.5$ & $5.5 \pm 0.4$ & $1.7 \pm 0.3$ & $0.0 \pm 0.3$ & 98 \\
\hline 120 & $119.6 \pm 2.4$ & $2.9 \pm 0.3$ & $0.6 \pm 0.5$ & $0.9 \pm 0.1$ & 99 \\
\hline
\end{tabular}

Respiratory mechanics measured on one rabbit while ventilating at varying target $\mathrm{RR}(30,40,60$, and 120 breaths/min) and maintaining constant pressure settings $\left(\mathrm{PIP}_{\text {target }}=11 \mathrm{cmH}_{2} \mathrm{O} ; \mathrm{PEEP}_{\text {target }}=3 \mathrm{cmH}_{2} \mathrm{O}\right)$ for 5 minutes each. Measured RR, VT, $\triangle \mathrm{PIP}$, and $\triangle \mathrm{PEEP}$ are presented as mean \pm standard deviation from the full duration of the 5-minute ventilation; $\mathrm{SpO}_{2}$ presented as mean $\mathrm{SpO} \mathrm{O}_{2}$ during the last minute of the 5-minute ventilation. $\triangle \mathrm{PIP}$ calculated as $\triangle \mathrm{PIP}=\mathrm{PIP}-\mathrm{PIP}_{\text {target}}$, and $\triangle \mathrm{PEEP}$ calculated as $\triangle \mathrm{PEEP}=\mathrm{PEEP}$ - PEEP target. PEEP positive end expiratory pressure, PIP peak inspiratory pressure, RR respiratory rate, $\mathrm{SpO}_{2}$ blood oxygen saturation, $\mathrm{V}_{\mathrm{T}}$ tidal volume. 
Furthermore, when the RR was increased from 30 to 120 breaths/min, the average minute $\mathrm{V}$, when sampled from the full 5 minutes, doubled from $173 \pm 1 \mathrm{~mL} / \mathrm{kg} / \mathrm{min}$ to $348 \pm 3 \mathrm{~mL} / \mathrm{kg} / \mathrm{min}$ (Figure 8). This led to a decrease in the average $\mathrm{EtCO}_{2}$, sampled from the last minute of ventilation, from $47 \pm 0 \mathrm{mmHg}$ to $32 \pm 1 \mathrm{mmHg}$.

\subsection{The FALCON PIP had greater short-term and long-term variability compared to the Carestation.}

Poincaré plots of the PIP and PEEP produced by the FALCON and Carestation were generated for each rabbit (a compiled Poincaré plot from all rabbits is shown in Figure 9a), and the short-term (SD1) and long-term (SD2) variations were calculated for each rabbit (Figure $9 \mathrm{~b}$ and $\mathbf{c}$ ). The FALCON generated significantly higher short-term and long-term variation in PIP compared to the Carestation, although the variation remained less than $1 \mathrm{~cm} \mathrm{H}_{2} \mathrm{O}$ (for SD1, $0.052 \pm 0.02 \mathrm{~cm} \mathrm{H}_{2} \mathrm{O}$ Carestation, $0.31 \pm 0.18 \mathrm{~cm} \mathrm{H}_{2} \mathrm{O}$ FALCON, ${ }^{*} p<$ 0.05 ; for SD2, $0.27 \pm 0.05 \mathrm{~cm} \mathrm{H}_{2} \mathrm{O}$ Carestation, $0.72 \pm 0.15 \mathrm{~cm} \mathrm{H}_{2} \mathrm{O}$ FALCON, $* \star p<0.01$ ). The short-term and long-term variation in PEEP generated by the FALCON were also less than $1 \mathrm{~cm} \mathrm{H_{2 }} O$ and trended higher than the PEEP from the Carestation (for SD1, 0.03 $\pm 0.01 \mathrm{~cm} \mathrm{H}_{2} \mathrm{O}$ Carestation, $0.23 \pm 0.18 \mathrm{~cm} \mathrm{H}_{2} \mathrm{O}$ FALCON, $p=0.06$; for SD2, $0.37 \pm 0.10 \mathrm{~cm} \mathrm{H}_{2} \mathrm{O}$ Carestation, $0.58 \pm 0.27 \mathrm{~cm} \mathrm{H} \mathrm{H}_{2} \mathrm{O}$ FALCON, $p=0.08$ ).

\subsection{Mechanical Ventilation from the FALCON and Carestation did not lead to VILI during short term ventilation.}

To assess the safety of ventilation with the FALCON, samples of lung tissue were taken after ventilation on both the Carestation and FALCON. Upon inspection after thoracotomy, no lungs appeared collapsed. Samples were then fixed and processed for H\&E staining (Figure 10a). A blinded pathologist examined the samples and scored for VILI (Figure 10b), which demonstrated no significant difference between the MV and SB rabbits ( $1.0 \pm 0.5 \mathrm{SB}, 1.6 \pm 0.7 \mathrm{MV}, p=0.13)$. Additionally, wet to dry weight ratios of the lung tissues (Figure 10c) showed no significant difference between the MV and SB groups (5.4 $\pm 0.3 \mathrm{SB}, 5.9 \pm 0.6 \mathrm{MV}, p=0.39$ ).

\section{Discussion}

In the present study, we compared ventilation with the FALCON and Carestation ventilators in a healthy rabbit lung model. We found that $V_{T}$, PIP, PEEP, and RR were comparable between the two ventilators. This validated our previous benchtop study that showed similarities between these approaches [28]. However, the present study showed that the measured I:E ratio on the FALCON was lower than the set value on the FALCON. This reflects delays in time spent by the turbine (1) accelerating from expiration to inspiration and

(2) decelerating from inspiration to expiration. Consequentially, $V_{T}$ was achieved more slowly, and the lungs remained fully expanded for a shorter time, possibly leading to the decreased oxygen uptake and carbon dioxide removal with the FALCON compared to the Carestation set at identical settings. We also showed that the FALCON can produce RRs (up to 120 breaths/min) much greater than that utilized in the crossover protocol (40 breaths/min) with a subsequent increase in minute ventilation, indicating that the settings can be easily altered to achieve favorable gas exchange.

The prolonged flow and pressure waveforms generated by the FALCON had been observed in other CEEVs [23, 27]. Crossover animal studies like ours in other CEEVs may reveal subtle, yet similar, differences between these and conventional ventilators. Such direct comparisons are valuable as they demonstrate how clinicians may need to adjust settings used on CEEVs to perform with similar efficacy to conventional ventilators.

On the Poincaré plot analysis, the FALCON demonstrated slightly higher short-term and long-term variations in PIP compared to the Carestation. This was likely due to the differences on how the PIP was generated. The Carestation generated pressures by regulating a high pressure gas source, such as a tank of oxygen or normal air, with electronically-driven pressure regulators and stepping the pressure down to the set pressure values [34], leading to highly reproducible PIP and PEEP. With the FALCON, PIP was generated by an accelerating air turbine. Even slight disparities in current delivered to the turbine may have led to differences in air speed produced by the turbine, resulting in the observed variations seen in PIP between one respiratory cycle and the next. In contrast, the PEEP in the FALCON was generated with a PEEP valve, which is a spring-loaded valve whose closing pressure was set independently of the FALCON's electronics [35]. This is likely why lower variations were observed with the FALCON's PEEP compared to its PIP, and why short-term and long-term variation was only trending higher with the FALCON's PEEP compared to the PEEP produced by the Carestation. Regardless, the short- and long-term variation of PIP and PEEP seen with the FALCON would not likely be noticeably different than the Carestation clinically, as both remained less than $1 \mathrm{~cm} \mathrm{H}_{2} \mathrm{O}$. 
There were no differences in wet to dry weight ratios or VILI scoring between the MV and SB groups. However, the relatively short ventilation time of one hour with each ventilator is not long enough to fully assess the longer-term safety profile of the FALCON. Many triggers of VILI-including barrier dysfunction [36], local pro-inflammatory pathway activation and leukocyte recruitment [37, 38], and oxidative stress [39]-occur secondary to the initial injury of mechanical trauma and hyperoxia [40-43], evolve over the course of hours to days, and can lead to multisystem organ injury and even failure, a process termed biotrauma [40, 44]. Nevertheless, any significant histological evidence of VILI was not observed over this short time-course. This study provides an initial proof-of-concept that the FALCON can be used as a mechanical ventilator without immediate devastating effects, such as pneumothorax, and may be useful in a longer-term scenario.

We chose to perform these initial experiments in a healthy animal lung model, as failure to adequately ventilate in healthy lungs would certainly mean failure in an ARDS model. Additionally, this allowed us to look for the presence of VILI without confounding evidence of lung injury incurred intentionally from a disease model. Future studies would involve the testing of the FALCON in an animal model with varying degrees of ARDS severity [45].

The rapid spread of SARS-CoV-2 virus infection and its variants has tested the global medical infrastructure. Life-saving tools, including mechanical ventilators, typically require extensive development, testing and manufacturing, all of which are timely and costly. Consequently, the normal supply of ventilators is typically kept relatively low, but this can create devastating shortages during critical surges. Development of impromptu medical devices, such as CEEVs, has exploded since the start of the pandemic, providing a valuable substitute in case of supply shortages $[11,12]$. Further studies into their efficacy and safety, such as the one presented here, and adherence to guidelines set forth by regulatory agencies, such as the US Food and Drug Administration [46] and the UK Medicines and Healthcare Product Regulatory Agency [47], can allow for development of emergency mechanical ventilator designs that can be rapidly, effectively, and more safely deployed in future surge crises, particularly in medical resource challenged areas. Additionally, our crossover study design in an animal model helped elucidate differences between a CEEV and conventional mechanical ventilator-for example, a difference in $\mathrm{EtCO}_{2}$-that may not be detected with benchtop testing.

Finally, it should be noted that the FALCON is not approved for human use under the United States Food and Drug Administration (FDA) or with any other regulatory agency and should not be used as a lifesaving therapy without further validation and approval.

\section{Conclusion}

The FALCON can successfully ventilate lungs in a healthy anesthetized rabbit model. Further studies are needed to determine the FALCON's potential use in ARDS. Although conventional mechanical ventilators are clearly preferable, our study demonstrates how CEEVs and future emergency ventilator designs can be tested and applied to rapidly enable access to ventilation.

\section{Abbreviations}

ABG: arterial blood gas

ARDS: acute respiratory distress syndrome

CEEV: Covid-19 era emergency ventilator

$\mathrm{EtCO}_{2}$ : end-tidal carbon dioxide

I:E: inspiratory time to expiratory time

MV: mechanical ventilation

$\mathrm{PaO}_{2}$ : arterial partial pressure of oxygen

$\mathrm{PaCO}_{2}$ : arterial partial pressure of carbon dioxide

PEEP: positive end expiratory pressure

PIP: peak inspiratory pressure

Page 9/19 
RR: respiratory rate

SB: spontaneously breathing

SD1: standard deviation 1 (short-term variation in Poincaré plot analysis)

SD2: standard deviation 2 (long-term variation in Poincaré plot analysis)

$\mathrm{SpO}_{2}$ : blood oxygen saturation

V: ventilation

$\mathrm{V}_{\mathrm{T}}$ : tidal volume

\section{Declarations}

Ethics Approval and Consent to Participate: The study conducted involved the use of rabbits and was performed with the approval of the Animal Care and Use Committee of LSU Health Shreveport (study protocol \#S-21-001). The study was performed in compliance with the Institution's policies involving the care and use of laboratory animals. All methods are reported in accordance with "Animal Research: Reporting of In Vivo Experiments" (ARRIVE) guidelines.

Consent for publication: not applicable

Availability of Data and Materials: The flow waveform datasets (Additional Files 1 through 10), pressure waveform datasets (Additional File 11), and other datasets (Additional File 12) analyzed, along with the custom Python code used to combine pressure waveforms (Additional File 13) and analyze the pressure and flow waveforms (Additional File 14) can be found in the supplementary material.

Competing Interests: The authors declare that they have no competing interests.

Funding: Funding was provided by the Department of Molecular and Cellular Physiology at LSU Health Shreveport. LW is the recipient of an LSU Health Shreveport "Ike Muslow Predoctoral Fellowship Award" related to this project.

Authors' Contributions: L.W. designed the study, conducted the experiments, and drafted the manuscript. B.M. contributed to the methodology and draft of the manuscript. H.T. analyzed and interpreted the histological samples and contributed to data analysis. G.S., S.C., and J.A. helped design and supervise the study and edited the manuscript. All authors read and approved the final manuscript.

Acknowledgements: The authors greatly appreciate Melissa Brown, RVT, and Donna Burney, DVM, for their technical expertise and aid with the surgical procedure, Debra Valentine, RRT, CRC, Tiffany McGaffey, RRT, and Troy Schleben, RRT, for their assistance with running the arterial blood gas samples, and for Pooja Veerareddy, Emma Dong, and Ruhani Sachdeva for their assistance with data collection.

Authors' Information: not applicable

\section{References}

1. Pneumonia of unknown cause - China. World Health Organization [Internet]. 2020 Jan 5 [cited 2021 Nov 30]; Available from: https://www.who.int/emergencies/disease-outbreak-news/item/2020-DON229. Accessed 30 Nov 2021.

2. WHO Director-General's opening remarks at the media briefing on COVID-19 [Internet]. 2020 March 11 [cited 2021 Nov 30]; Available from: https://www.who.int/director-general/speeches/detail/who-director-general-s-opening-remarks-at-the-mediabriefing-on-covid-19-11-march-2020

3. Huang C, Wang Y, Li X, Ren L, Zhao J, Hu Y, et al. Clinical features of patients infected with 2019 novel coronavirus in Wuhan, China. The Lancet. 2020 Feb;395(10223):497-506. https://doi.org/10.1016/S0140-6736(20)30183-5 
4. Wang D, Hu B, Hu C, Zhu F, Liu X, Zhang J, et al. Clinical Characteristics of 138 Hospitalized Patients With 2019 Novel Coronavirus-Infected Pneumonia in Wuhan, China. JAMA. 2020 Mar 17;323(11):1061.

https://dx.doi.org/10.1001\%2Fjama.2020.1585

5. Grasselli G, Zangrillo A, Zanella A, Antonelli M, Cabrini L, Castelli A, et al. Baseline Characteristics and Outcomes of 1591 Patients Infected With SARS-CoV-2 Admitted to ICUs of the Lombardy Region, Italy. JAMA. 2020 Apr 28;323(16):1574. https://doi.org/10.1001/jama.2020.5394

6. Haudebourg A-F, Perier F, Tuffet S, de Prost N, Razazi K, Mekontso Dessap A, et al. Respiratory Mechanics of COVID-19-versus Non-COVID-19-associated Acute Respiratory Distress Syndrome. Am J Respir Crit Care Med. 2020 Jul 15;202(2):287-90. https://doi.org/10.1164/rccm.202004-1226le

7. Emanuel EJ, Persad G, Upshur R, Thome B, Parker M, Glickman A, et al. Fair Allocation of Scarce Medical Resources in the Time of Covid-19. N Engl J Med. 2020 May 21;382(21):2049-55. https://doi.org/10.1056/nejmsb2005114

8. White DB, Lo B. A Framework for Rationing Ventilators and Critical Care Beds During the COVID-19 Pandemic. JAMA. 2020 May 12;323(18):1773. https://doi.org/10.1001/jama.2020.5046

9. Guérin C, Lévy P. Easier access to mechanical ventilation worldwide: an urgent need for low income countries, especially in face of the growing COVID-19 crisis. Eur Respir J. 2020 Jun;55(6):2001271. https://dx.doi.org/10.1183\%2F13993003.01271-2020

10. Murthy S, Adhikari NK. Global health care of the critically ill in low-resource settings. Ann Am Thorac Soc. 2013 Oct;10(5):50913. https://doi.org/10.1513/annalsats.201307-246ot

11. Pearce JM. A review of open source ventilators for COVID-19 and future pandemics. F1000Res. 2020 Apr 30;9:218. https://dx.doi.org/10.12688\%2Ff1000research.22942.2

12. Nacharaju D, Menzel W, Fontaine E, Child D, El Haddi SJ, Nonas S, et al. Three-Dimensional Printed Ventilators: A Rapid Solution to Coronavirus Disease 2019-Induced Supply-Chain Shortages. Critical Care Explorations. 2020 Oct 2;2(10):e0226.

https://dx.doi.org/10.1097\%2FCCE.0000000000000226

13. Frederick J. White III. The Prioritization of Life- Saving Resources in a Pandemic Surge Crisis. Issues in Law and Medicine. 35(1/2):99-116.

14. Haina KMK. Use of Anesthesia Machines in a Critical Care Setting During the Coronavirus Disease 2019 Pandemic. A\&A Practice. 2020 May;14(7):e01243. https://dx.doi.org/10.1213\%2FXAA.0000000000001243

15. Bottiroli M, Calini A, Pinciroli R, Mueller A, Siragusa A, Anelli C, et al. The repurposed use of anesthesia machines to ventilate critically ill patients with coronavirus disease 2019 (COVID-19). BMC Anesthesiol. 2021 Dec;21(1):155. https://doi.org/10.21203/rs.3.rs-228821/v1

16. Ranney ML, Griffeth V, Jha AK. Critical Supply Shortages - The Need for Ventilators and Personal Protective Equipment during the Covid-19 Pandemic. N Engl J Med. 2020 Apr 30;382(18):e41. https://doi.org/10.1056/nejmp2006141

17. Bhaskar S, Tan J, Bogers MLAM, Minssen T, Badaruddin H, Israeli-Korn S, et al. At the Epicenter of COVID-19-the Tragic Failure of the Global Supply Chain for Medical Supplies. Front Public Health. 2020;8:562882. https://doi.org/10.3389/fpubh.2020.562882

18. MIT Emergency Ventilator Project [Internet]. [cited 2021 Nov 30]; Available from: https://emergency-vent.mit.edu

19. Blacker D, Oden M, Wettergreen M, Herring T, Kavalewitz A, Malya R, et al. ApolloBVM - Emergency Use Ventilator [Internet]. [cited 2021 Nov 30]; Available from: http://oedk.rice.edu/apollobvm/

20. Read RL, Dario H, Pintarelli GB, Baskaran A, O’Donnell R, Zintz E, et al. covid19-vent-list [Internet]. [cited 2021 Nov 30]; Available from: https://github.com/Publnv/covid19-vent-list

21. Finkle A. Gitlab. OpenLung BVM ventilator [Internet]. [cited 2021 Nov 30]; Available from: https://gitlab.com/open-sourceventilator/ventilator/OpenLung

22. Dhanani J, Pang G, Pincus J, Ahern B, Goodwin W, Cowling N, et al. Increasing ventilator surge capacity in COVID 19 pandemic: design, manufacture and in vitro-in vivo testing in anaesthetized healthy pigs of a rapid prototyped mechanical ventilator. BMC Res Notes. 2020 Sep 7;13(1):421. https://dx.doi.org/10.1186\%2Fs13104-020-05259-z

23. Garmendia O, Rodríguez-Lazaro MA, Otero J, Phan P, Stoyanova A, Dinh-Xuan AT, et al. Low-cost, easy-to-build noninvasive pressure support ventilator for under-resourced regions: open source hardware description, performance and feasibility testing. Eur Respir J. 2020 Jun;55(6):2000846. https://doi.org/10.1183/13993003.00846-2020

Page $11 / 19$ 
24. Kwon AH, Slocum AH, Varelmann D, Nabzdyk CGS, on behalf of the MIT E-Vent Team, Araki B, et al. Rapidly scalable mechanical ventilator for the COVID-19 pandemic. Intensive Care Med. 2020 Aug;46(8):1642-4. https://doi.org/10.1007/s00134-020-061133

25. Christou A, Ntagios M, Hart A, Dahiya R. GlasVent-The Rapidly Deployable Emergency Ventilator. Global Challenges. 2020 Dec;4(12):2000046. https://doi.org/10.1002/gch2.202000046

26. Zuckerberg J, Shaik M, Widmeier K, Kilbaugh T, Nelin TD. A lung for all: Novel mechanical ventilator for emergency and lowresource settings. Life Sciences. 2020 Sep;257:118113. https://doi.org/10.1016/j.lfs.2020.118113

27. King WP, Amos J, Azer M, Baker D, Bashir R, Best C, et al. Emergency ventilator for COVID-19. Schmölzer GM, editor. PLoS ONE. 2020 Dec 30;15(12):e0244963. https://doi.org/10.1371/journal.pone.0244963

28. White LA, Mackay RP, Solitro GF, Conrad SA, Alexander JS. Construction and Performance Testing of a Fast-Assembly COVID-19 (FALCON) Emergency Ventilator in a Model of Normal and Low-Pulmonary Compliance Conditions. Front Physiol. 2021;12:642353. https://doi.org/10.3389/fphys.2021.642353

29. Sealed Envelope Ltd. 2021. Create a blocked randomisation list. [Online] [Accessed 20 July 2021]. Available from: https://www.sealedenvelope.com/simple-randomiser/v1/lists

30. Qu W-S, Yin J-Y, Wang H-M, Dong Y-S, Ding R-G. A simple method for the formalin fixation of lungs in toxicological pathology studies. Experimental and Toxicologic Pathology. 2015 Oct;67(10):533-8. https://doi.org/10.1016/j.etp.2015.08.002

31. Wolthuis EK, Vlaar AP, Choi G, Roelofs JJ, Juffermans NP, Schultz MJ. Mechanical ventilation using non-injurious ventilation settings causes lung injury in the absence of pre-existing lung injury in healthy mice. Crit Care. 2009;13(1):R1. https://doi.org/10.1186/cc7688

32. Satti R, Abid N-U-H, Bottaro M, De Rui M, Garrido M, Raoufy MR, et al. The Application of the Extended Poincaré Plot in the Analysis of Physiological Variabilities. Front Physiol. 2019 Feb 19;10:116. https://doi.org/10.3389/fphys.2019.00116

33. Dhand, N. K., \& Khatkar, M. S. Statulator: An online statistical calculator. Sample Size Calculator for Comparing Two Paired Means [Internet]. 2014 [cited 2021 December 7]; Available from: http://statulator.com/SampleSize/ss2PM.html

34. Enström Ventilator Technical Reference Manual. Datex-Ohmeda, Inc.; 2004. https://www.medonegroup.com/pdf/manuals/techManuals/Datex-Ohmeda-Engstrom-VentilatorTechnical-Manual.pdf. Accessed 30 Nov 2021.

35. Tracy M, Shah D, Priyadarshi A, Hinder M. The effectiveness of Ambu neonatal self-inflating bag to provide consistent positive end-expiratory pressure. Arch Dis Child Fetal Neonatal Ed. 2016 Sep;101(5):F439-43. https://doi.org/10.1136/archdischild2015-308649

36. Wang T, Gross C, Desai AA, Zemskov E, Wu X, Garcia AN, et al. Endothelial cell signaling and ventilator-induced lung injury: molecular mechanisms, genomic analyses, and therapeutic targets. American Journal of Physiology-Lung Cellular and Molecular Physiology. 2017 Apr 1;312(4):L452-76. https://doi.org/10.1152/ajplung.00231.2016

37. Lionetti V, Recchia FA, Marco Ranieri V. Overview of ventilator-induced lung injury mechanisms. Current Opinion in Critical Care. 2005 Feb;11(1):82-6. https://doi.org/10.1097/00075198-200502000-00013

38. Zhang H, Downey GP, Suter PM, Slutsky AS, Ranieri VM. Conventional Mechanical Ventilation Is Associated with Bronchoalveolar Lavage-induced Activation of Polymorphonuclear Leukocytes. Anesthesiology. 2002 Dec 1;97(6):1426-33. https://doi.org/10.1097/00000542-200212000-00014

39. Kallet RH, Matthay MA. Hyperoxic Acute Lung Injury. Respiratory Care. 2013 Jan 1;58(1):123-41. https://doi.org/10.4187/respcare.01963

40. Tremblay LN, Slutsky AS. Ventilator-induced injury: from barotrauma to biotrauma. Proc Assoc Am Physicians. 1998 Dec;110(6):482-8.

41. Dreyfuss D, Saumon G. Ventilator-induced Lung Injury: Lessons from Experimental Studies. Am J Respir Crit Care Med. 1998 Jan;157(1):294-323. https://doi.org/10.1164/ajrccm.157.1.9604014

42. Rocco PRM, Dos Santos C, Pelosi P. Pathophysiology of ventilator-associated lung injury. Current Opinion in Anaesthesiology. 2012 Apr;25(2):123-30. https://doi.org/10.1097/aco.0b013e32834f8c7f

43. Amarelle L, Quintela L, Hurtado J, Malacrida L. Hyperoxia and Lungs: What We Have Learned From Animal Models. Front Med. 2021 Mar 9;8:606678. https://doi.org/10.3389/fmed.2021.606678

Page $12 / 19$ 
44. Curley GF, Laffey JG, Zhang H, Slutsky AS. Biotrauma and Ventilator-Induced Lung Injury. Chest. 2016 Nov;150(5):1109-17. https://doi.org/10.1016/j.chest.2016.07.019

45. ARDS Definition Task Force, Ranieri V, Rubenfeld G, Thompson B, Ferguson N, Caldwell E, et al. Acute Respiratory Distress Syndrome: The Berlin Definition. JAMA. 2012 Jun 20;307(23). https://doi.org/10.1001/jama.2012.5669

46. Ventilators and Ventilator Accessories EUAs. U.S. Food and Drug Administration [Internet]. 2021 Jul 7 [cited 2021 Nov 30 ]; Available from: https://www.fda.gov/medical-devices/coronavirus-disease-2019-covid-19-emergency-use-authorizationsmedical-devices/ventilators-and-ventilator-accessories-euas

47. Rapidly Manufactured Ventilator System (RMVS). Medicines and Healthcare Products Regulatory Agency [Internet]. 2020 Oct [cited 2021 Nov 30]; Available from:

https://assets.publishing.service.gov.uk/government/uploads/system/uploads/attachment_data/file/879382/RMVS001_v4.pdf

\section{Figures}
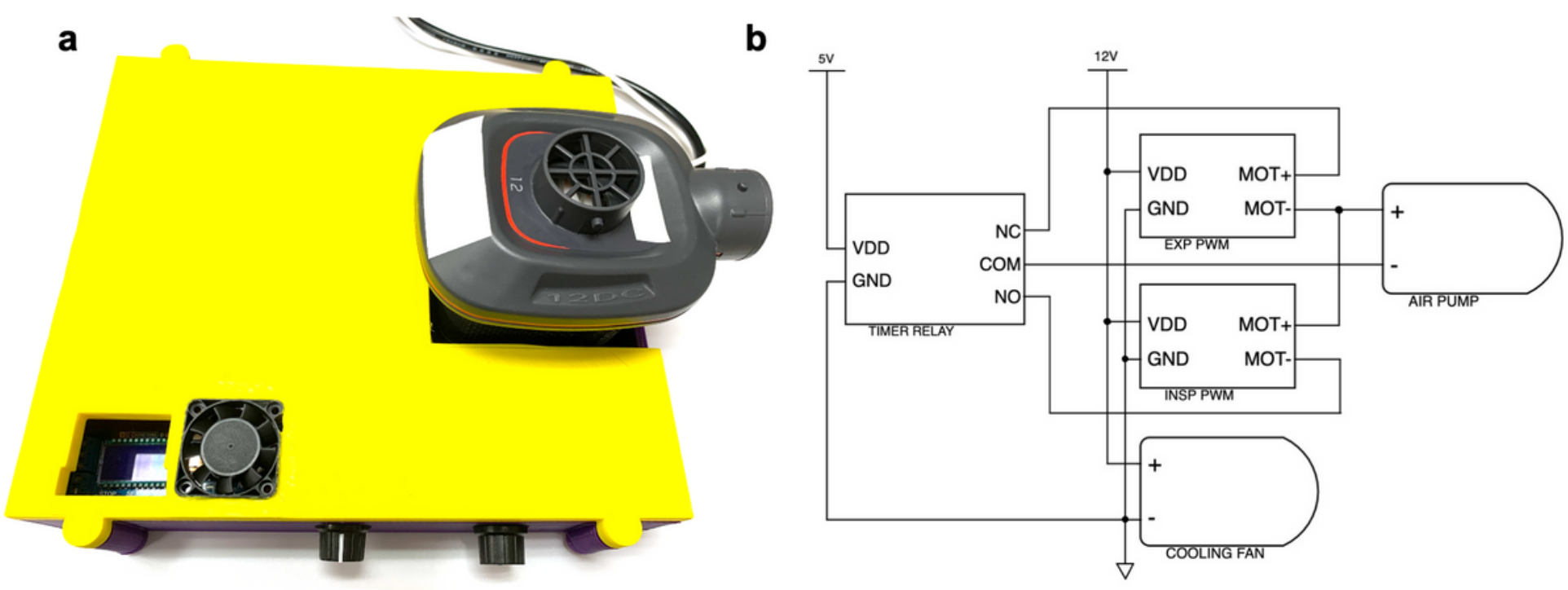

\section{Figure 1}

(a) Prototype of the FALCON ventilator, modified from the previously published design (see text for details). (b) Wiring schematic for the modified FALCON ventilator. 5V/12V five/twelve-volt power supply, COM common, EXP PWM expiratory pulse width modulator, GND ground, INSP PWM inspiratory pulse width modulator, MOT+/- positive/negative motor, NC normally closed, NO normally open, VDD voltage drain drain. 


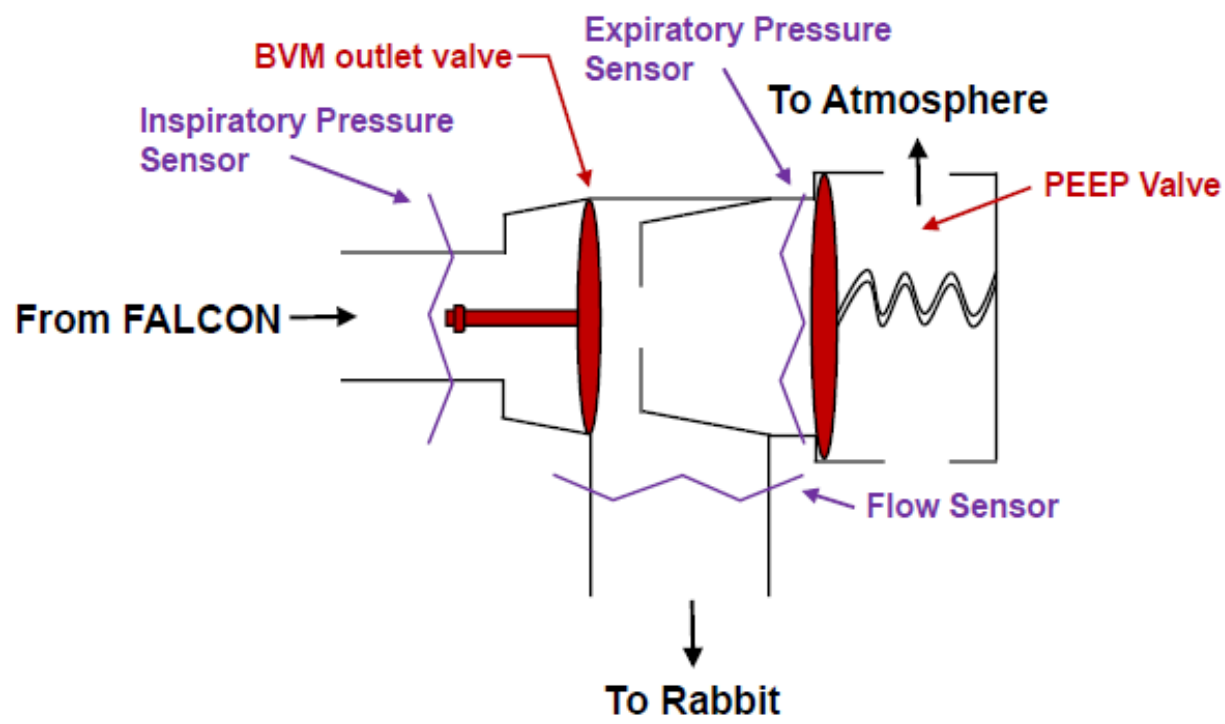

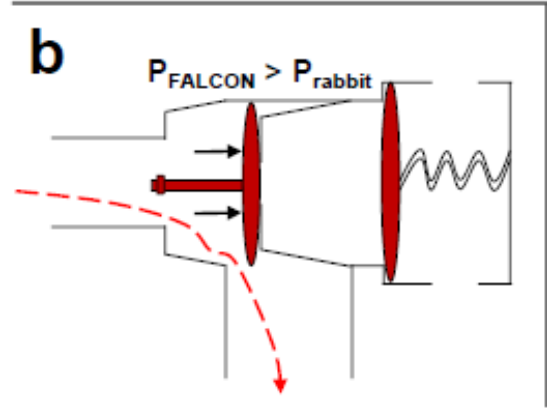

INSPIRATION

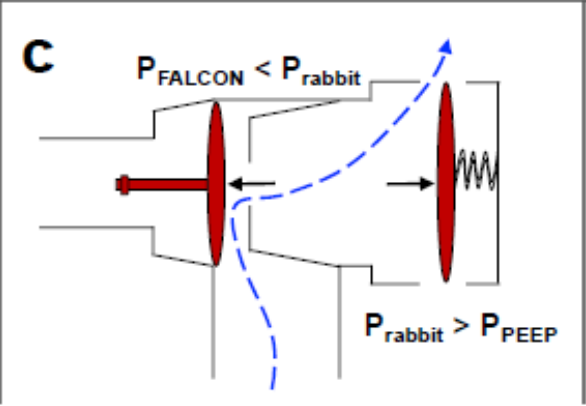

START OF EXPIRATION

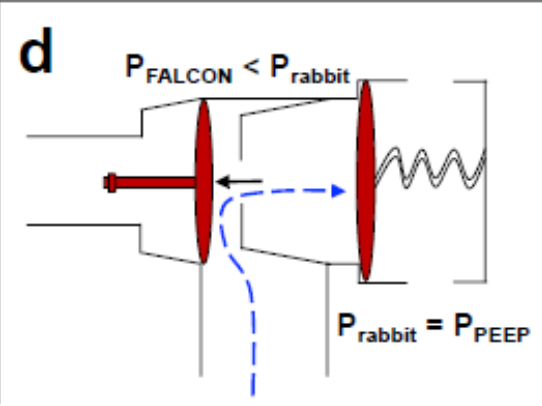

END OF EXPIRATION

\section{Figure 2}

Schematic of the three-way, two-position pneumatically driven ventilator valve from the outlet side of an infant BVM used with the FALCON. (a) The FALCON was connected to the inspiratory side of the valve with a barometric pressure sensor to capture inspiratory pressure waveforms, and a PEEP valve was connected to the expiratory side with a second pressure sensor to capture expiratory pressure waveforms. The common line was used to connect the ventilator circuit to the rabbit, and a flow sensor was placed between the valve and rabbit to capture flow waveforms. (b) During inspiration, the FALCON's air pump generated a positive pressure (PFALCON) which was greater than the airway pressure in the rabbit (Prabbit), causing the valve to open between the inspiratory side and the common and air to flow into the rabbit lungs. (c) During expiration, the turbine in the air pump rapidly slowed down, and PFALCON rapidly dropped below the Prabbit, at which point the valve shut towards the inspiratory limb and opened to the expiratory outlet, allowing outflow of air from the rabbit lungs into atmosphere. (d) When Prabbit reached the pressure set on the PEEP valve (PPEEP), the PEEP valve closed, and air ceased to flow out of the rabbit lungs.

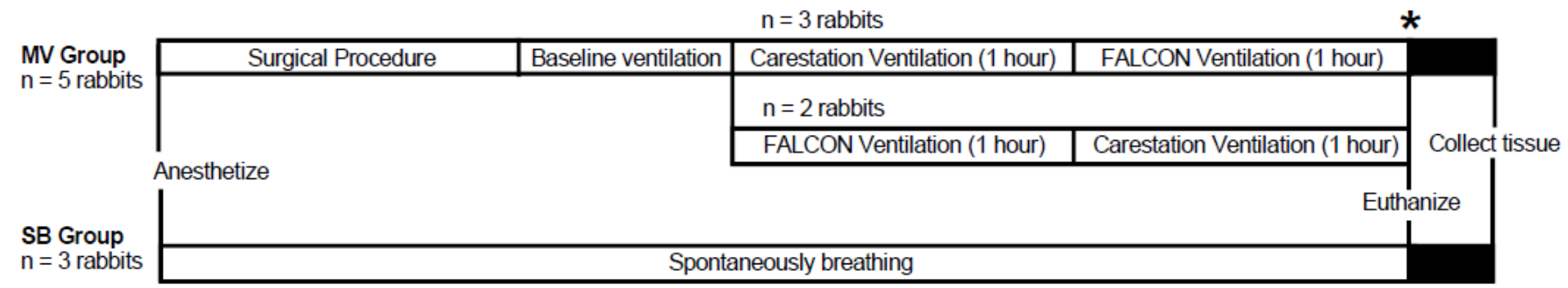

$\mathrm{n}=1$ rabbit

* FALCON Ventilation at varying RRs $\left(30,40,60,120\right.$ min $\left.^{-1}\right)$ for 5 min each 
Figure 3

Experimental study design. Five rabbits underwent the experimental procedure (MV group). After anesthesia induction, the rabbits underwent the surgical procedure (see text for details) followed by baseline ventilation on the Carestation to determine ventilation settings for the remainder of the experiment. Afterwards, a subgroup of rabbits $(n=3)$ was ventilated with the Carestation first followed by the FALCON, the rest $(n=2)$ ventilated in the reverse order. One rabbit (indicated by *) was further ventilated on the FALCON at varying respiratory rates (at 30, 40, 60, and 120 breaths/min) for 5 minutes each. After ventilation, the rabbits were euthanized, and lung tissue samples were collected. Three spontaneously breathing rabbits (SB group) were anesthetized and euthanized for healthy lung tissue collection.

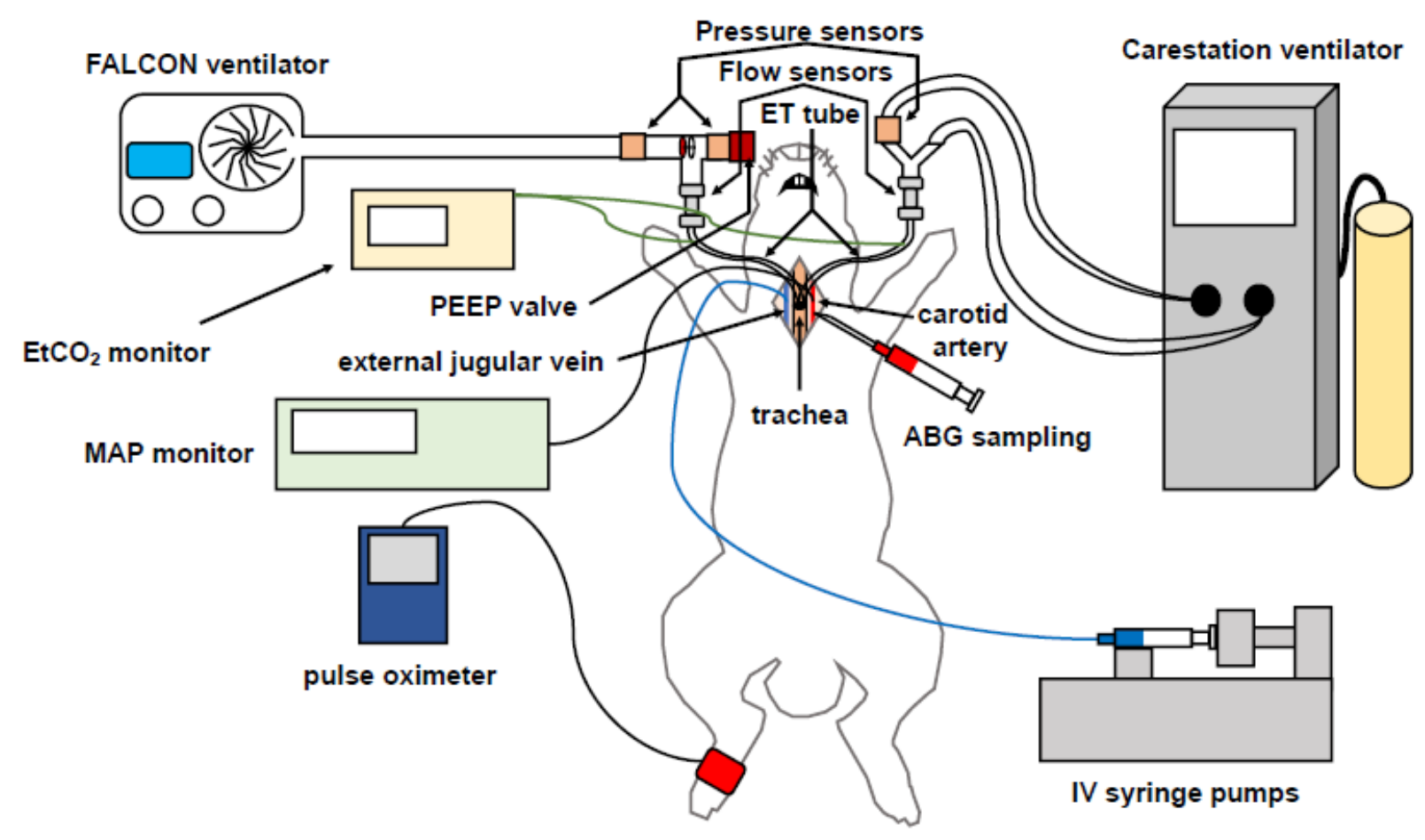

Figure 4

Experimental setup; see text for further details. ABG arterial blood gas, ET endotracheal, EtCO2 end tidal carbon dioxide, IV intravenous, MAP mean arterial pressure, PEEP positive end expiratory pressure. 

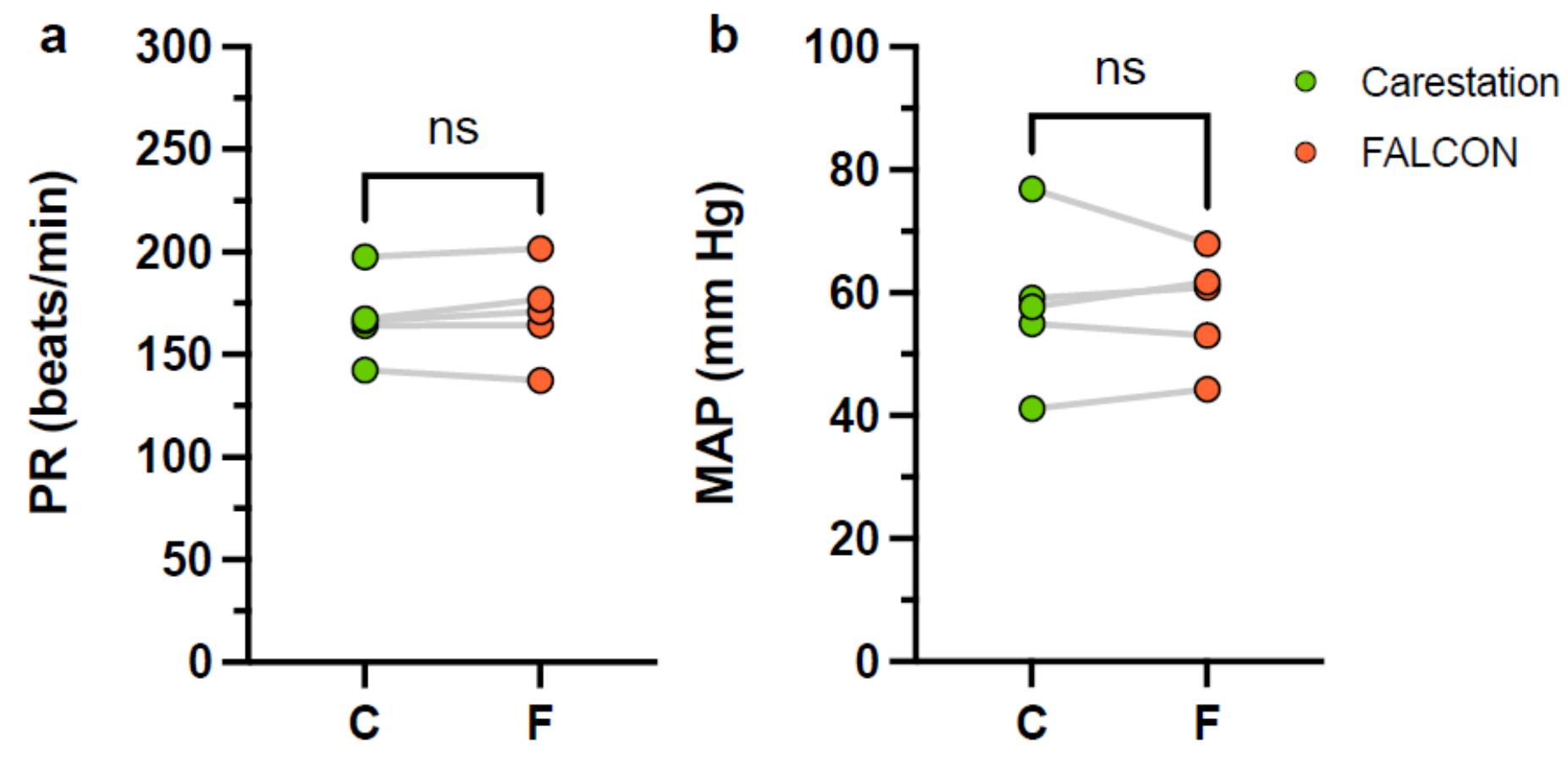

Figure 5

PR (a) and MAP (b) during ventilation with the Carestation (green) and FALCON (orange, $\mathrm{n}=5$ rabbits, two-tailed paired Students ttest, $a=0.05)$. MAP mean arterial pressure, NS not significant, PR pulse rate.
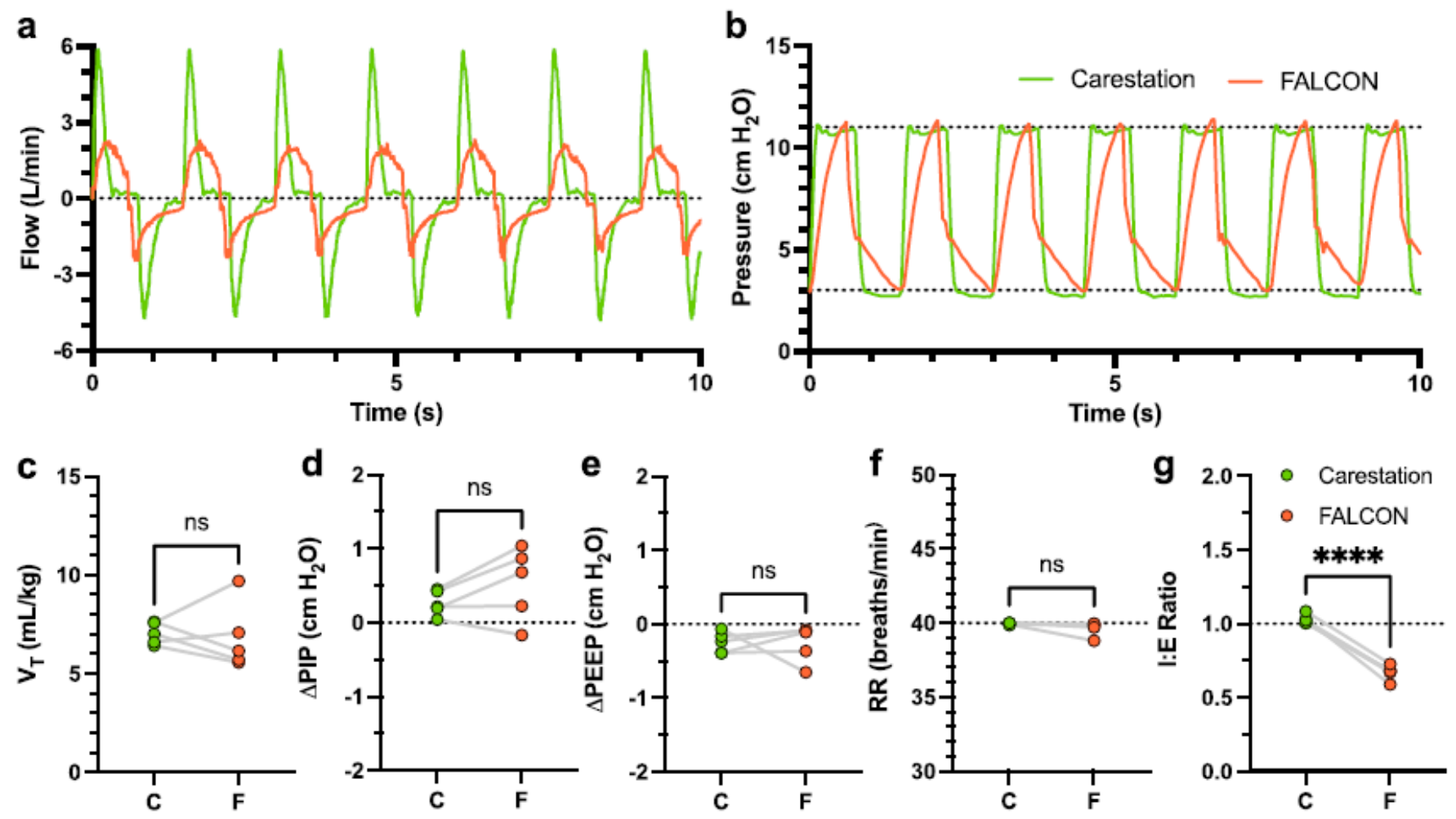

Figure 6

Representative flow (a) and pressure (b) waveforms generated by the Carestation (green line) and FALCON (orange) sampled over 10 seconds. VT (c), $\triangle P I P(d), \triangle P E E P(e), R R(f)$, and I:E ratio (g) derived from the average of 1-minute samples taken every 10 minutes for the duration of ventilation are shown for the Carestation (green) and FALCON (orange). $\triangle \mathrm{PIP}$ calculated as $\triangle \mathrm{PIP}=\mathrm{PIP}-$ 
PIPtarget, and $\triangle \mathrm{PEEP}$ calculated as $\triangle \mathrm{PEEP}=\mathrm{PEEP}-\mathrm{PEEPtarget}$. Either two-tailed paired Students t-test $(\mathrm{VT}, \triangle \mathrm{PIP}, \triangle \mathrm{PEEP}$, and I:E ratio) or Wilcoxon signed rank test $(R R)$ were performed $(n=5$ rabbits, $a=0.05)$. ${ }^{* \star *} p<0.0001$, I:E inspiratory time to expiratory time, NS not significant, PEEP positive end expiratory pressure, PIP peak inspiratory pressure, RR respiratory rate, VT tidal volume.

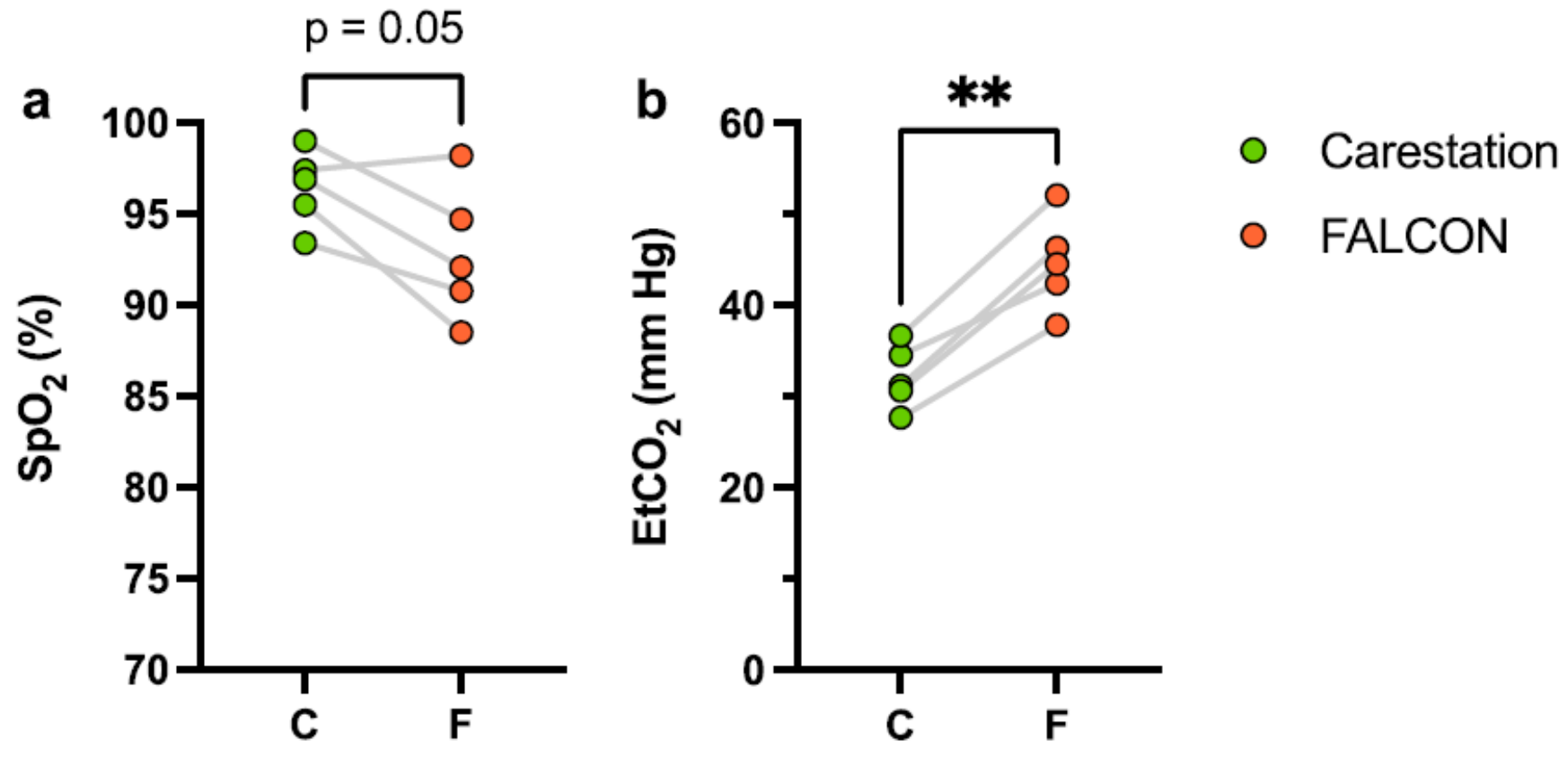

Figure 7

Average SpO2 (a) and EtCO2 (b) during ventilation with the Carestation and FALCON ( $\mathrm{n}=5$ rabbits, two-tailed paired Students t-test, $a=0.05) .{ }^{\star *} p<0.01$, EtCO2 end tidal carbon dioxide, SpO2 blood oxygen saturation.

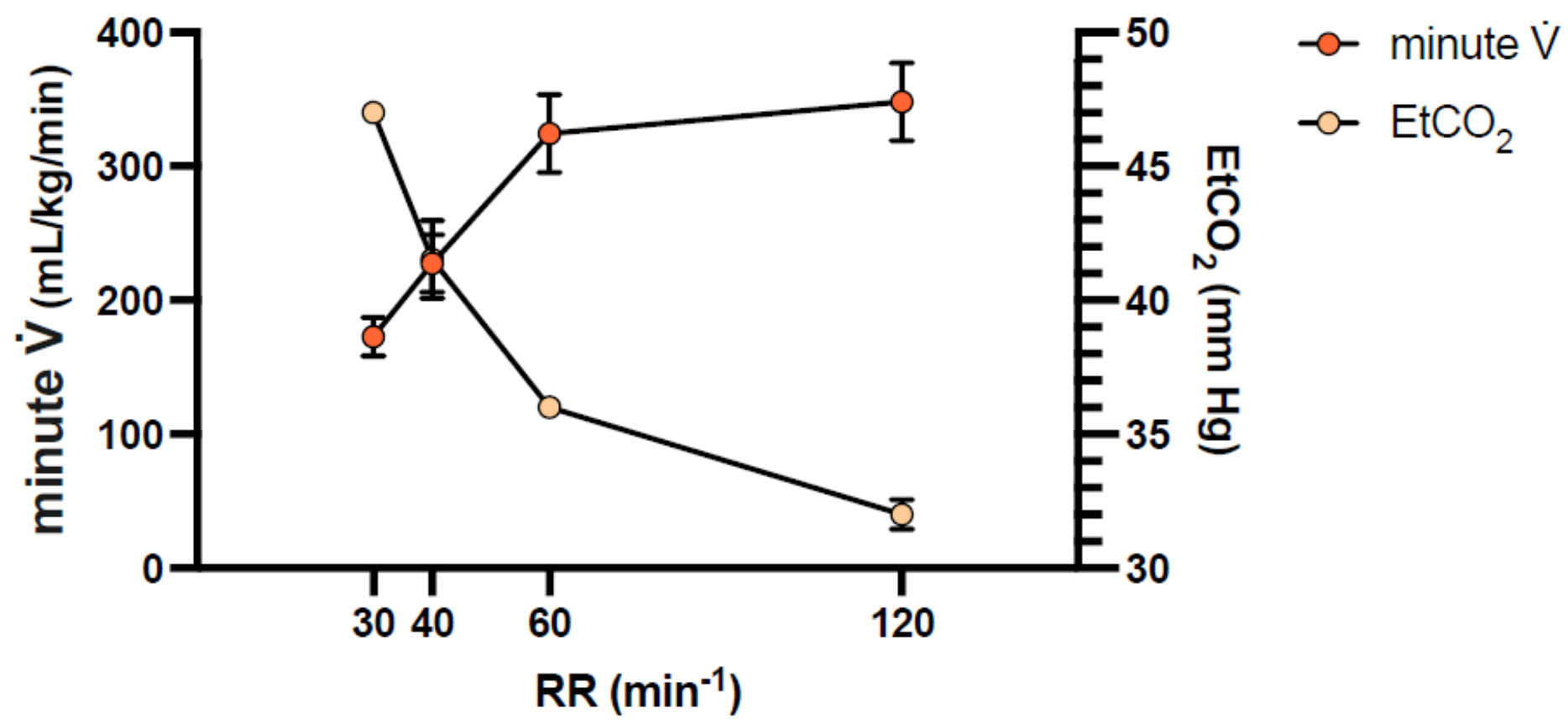

Figure 8

Results of minute $\mathrm{V}$ and EtCO2 of a rabbit $(\mathrm{n}=1)$ during mechanical ventilation with the FALCON for 5 minutes at varying target RRs $(30,40,60$, and 120 breaths $/ \mathrm{min}$ ) with constant pressure settings (PIPtarget $=11 \mathrm{~cm} \mathrm{H} 2 \mathrm{O}$; PEEPtarget $=3 \mathrm{~cm} \mathrm{H2O}$ ). Minute V 
presented is the mean minute $\mathrm{V}$ from each full 5-minute period. EtCO2 presented is the mean EtCO2 for the last minute of each 5minute ventilation period. Error bars, where present, indicate standard deviation. EtCO2 end tidal carbon dioxide, PEEPtarget target positive end expiratory pressure, PIPtarget target peak inspiratory pressure, RR respiratory rate, $\mathrm{V}$ ventilation.
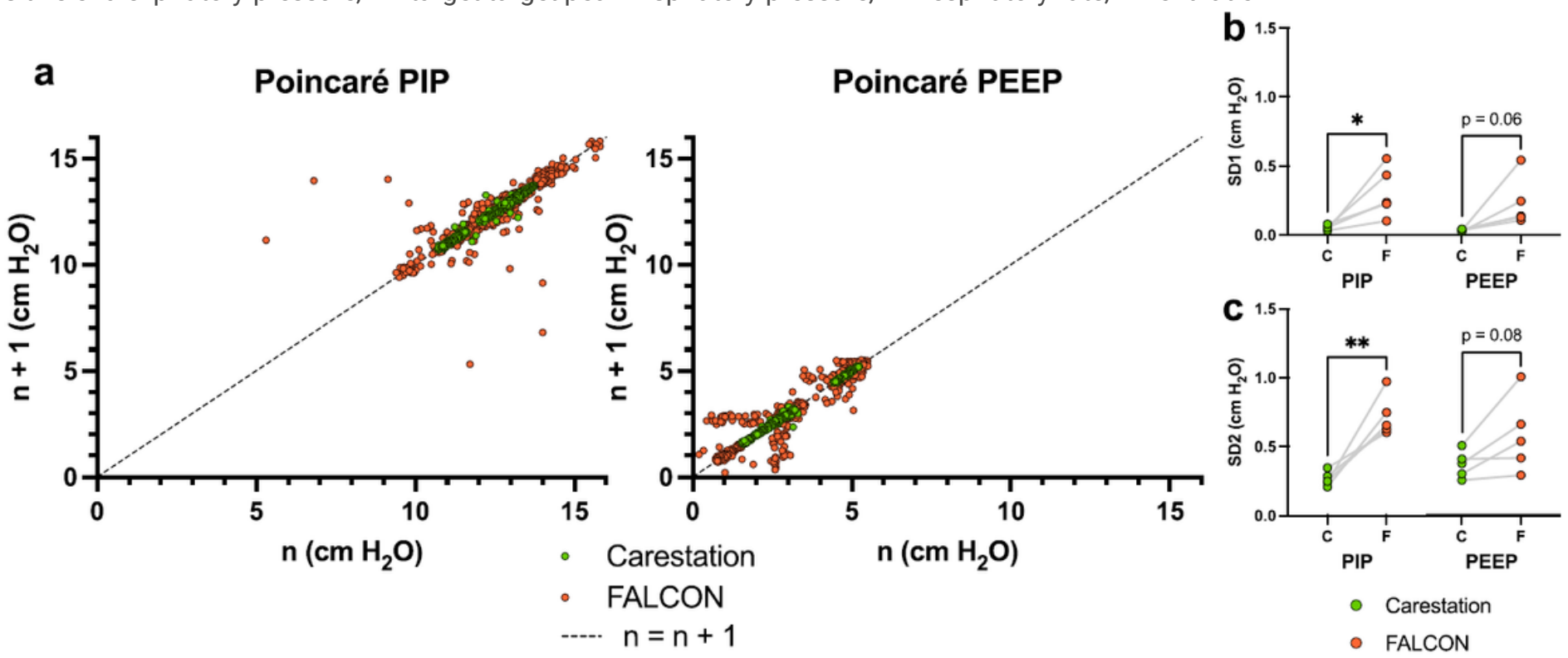

Figure 9

(a) Poincaré plots of PIP and PEEP with both the FALCON and Carestation compiled from all rabbits ventilated $(n=5$ rabbits). Dotted line indicates the line of identity $(n=n+1)$. Average SD1 (b) and SD2 (c) for each rabbit ventilated with the FALCON and Carestation. Either a two-tailed paired Students t-test (SD1 PIP, SD2 PIP, and SD2 PEEP) or Wilcoxon signed rank test (SD1 PEEP) were performed $(n=5$ rabbits, $a=0.05) .{ }^{*} p<0.05,{ }^{\star} * p<0.01$, PEEP positive end expiratory pressure, PIP peak inspiratory pressure.
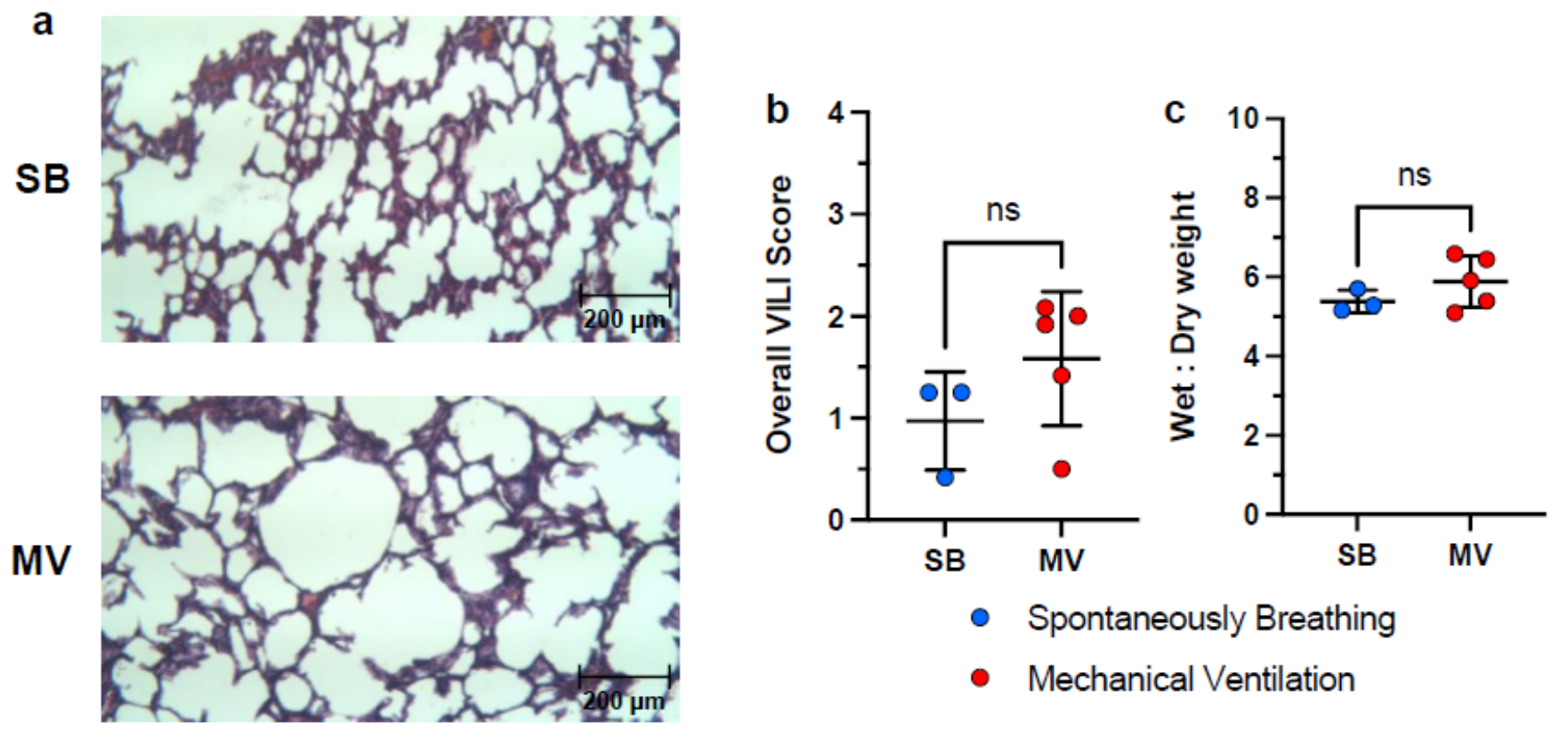

- Spontaneously Breathing
- Mechanical Ventilation

Figure 10

(a) Representative H\&E staining (100x). (b) VILI overall histology score from lung samples (right posterior lobe) of spontaneously breathing rabbits $(S B, n=3)$ and rabbits mechanically ventilated $(M V, n=5)$ with both the Carestation and FALCON (two-tailed Mann- 
Whitney $U$ test, $a=0.05$ ). (c) Lung wet weight to dry weight ratio (two-tailed Mann-Whitney $U$ test, $a=0.05$ ). H\&E hematoxylin and eosin, MV mechanical ventilation, NS not significant, SB spontaneously breathing.

\section{Supplementary Files}

This is a list of supplementary files associated with this preprint. Click to download.

- AdditionalFile1.xlsx

- AdditionalFile2.xlsx

- AdditionalFile3.xlsx

- AdditionalFile4.xlsx

- AdditionalFile5.xlsx

- AdditionalFile6.xlsx

- AdditionalFile7.xlsx

- AdditionalFile8.xlsx

- AdditionalFile9.xlsx

- AdditionalFile10.xlsx

- AdditionalFile11.xIsx

- AdditionalFile12.xIsx

- AdditionalFile13.py

- AdditionalFile14.py 